\title{
Effects of aerobic exercise and vitamin C supplementation on rhinitis symptoms in allergic rhinitis patients
}

\author{
Wannaporn Tongtako, ${ }^{1}$ Jettanong Klaewsongkram, ${ }^{2}$ Timothy D. Mickleborough, ${ }^{3}$ Daroonwan Suksom ${ }^{1 *}$
}

\begin{abstract}
Introduction: Exercise training and vitamin C supplementation have both been recommended as an effective adjuvant treatment in the management of symptoms in patients with many diseases. However, its effects on rhinitis symptoms remain unclear. The aim of the present study was to determine the effects of exercise training alone, and in combination with vitamin $\mathrm{C}$ supplementation, on rhinitis symptoms in allergic rhinitis patients.
\end{abstract}

Methods: Twenty-seven rhinitis patients were randomized into 3 groups: control (CON; $n=8)$, exercise $(E X ; n=9)$, and exercise combined with vitamin C $(\mathrm{EX}+\mathrm{Vit} . \mathrm{C} ; \mathrm{n}=10)$. The exercise training protocol consisted of walking and/or running on a treadmill at $65-70 \%$ heart rate reserve for 30 min per session, 3 times per week for 8 weeks. The EX + Vit.C group ingested 2,000 mg vitamin C per day.

Results: After 8 weeks, both EX and EX + Vit.C groups increased peak aerobic capacity and peak nasal inspiratory flow (PNIF) and exhibited significantly decreased rhinitis symptoms, nasal blood flow (NBF) and malondialdehylde levels compared to pre-test. Rhinitis symptoms and NBF after nasal challenge with house dust mite decreased significantly in the EX and EX + Vit.C groups. The EX and EX + Vit.C groups had significantly lower nasal secretion interleukin (IL)-4, but higher nasal secretion IL-2 levels, than the CON group.

Conclusions: This study clearly confirms that aerobic exercise training significantly improved clinical of allergic rhinitis and cytokine profiles. Nonetheless, with the limited power of small sample size, whether adding vitamin $\mathrm{C}$ is any beneficial is not shown. A larger randomized controlled trial is thus warranted.

Key words: Nasal inspiratory flow, Nasal blood flow, Cytokine levels, Malondialdehylde, Nasal challenge

From:

${ }^{1}$ Faculty of Sports Science, Chulalongkorn University, Bangkok, Thailand.

2 Division of Allergy and Clinical Immunology, Department of Medicine, Faculty of Medicine, Allergy and Clinical Immunology Research Group, Chulalongkorn University, Bangkok, Thailand.

Department of Kinesiology, School of Public Health, Indiana University, Bloomington, Indiana, USA.

\section{Introduction}

Allergic rhinitis is a prevalent disease caused by a malfunction of the immune system in response to a hypersensitive reaction to allergic allergens in the nasal mucosa, which is characterized by itching, nasal congestion, sneezing, and rhinorrhea. ${ }^{1}$ In the nose, allergens are targeted by allergen -specific immunoglobulin E (IgE) which bind to $\operatorname{IgE}$ receptors on mast cells and basophils and release chemical mediators such as histamine, leukotrienes, and cytokines which can cause symptoms of allergic rhinitis to develop. ${ }^{2}$ A number of recent studies have shown an increase of IL-4 level in allergic rhinitis patients. Alternatively, IL-2 induces macrophage activation,

\author{
* Corresponding author: \\ Daroonwan Suksom \\ Faculty of Sports Science, Chulalongkorn University \\ Rama 1 Rd, Patumwam, Bangkok 10330 Thailand \\ E-mail: daroonwanc@hotmail.com
}

which is very effective in controlling infection along with intracellular pathogens. Patients suffering from allergic rhinitis have to cope with the discomfort, the cost of nasal and oral medications and their associated side-effects, and a worsening quality of life. ${ }^{3}$

Aerobic exercise has been recommended as an effective adjuvant treatment in the management of symptoms in patients with a variety of disease states. ${ }^{4-7}$ However, previous studies have demonstrated that acute high-intensity exercise can cause a worsening of rhinitis symptoms. ${ }^{8}$ Moreover, high-intensity exercise has been shown to decrease forced expiratory volume 
in 1 second $\left(\mathrm{FEV}_{1}\right),{ }^{9}$ and increase $\operatorname{IgE}$ levels ${ }^{10}$ in patients with allergic rhinitis. Recently, Tongtako et al. ${ }^{11}$ reported that both acute exhaustive and moderate-intensity exercise reduced allergic rhinitis symptoms. However, a significantly enhanced IL-2/IL-4 ratio was found following acute moderate exercise. Since IL-2 is critical for supporting $\mathrm{T}$ cell activation, preventing autoimmunity and controlling infection along with intracellular pathogens effectively while IL- 4 act as a coordinator of airway inflammatory processes in allergic disorders. In addition, Silva et al. $^{12}$ have reported that aerobic exercise training increased plasma IgE and reduced eosinophils, IL-4, IL-5, IL-13, airway remodeling, mucus synthesis, the thickness of smooth muscle and nasal resistance in a chronic murine model of allergic airway disease. Therefore, based on the available evidence aerobic exercise training may have a beneficial effect in terms of controlling rhinitis symptoms. ${ }^{11-12}$

Vitamin C (ascorbic acid) is an important antioxidant in the body and has been used to prevent and treat various diseases. ${ }^{13-15}$ It has been suggested that vitamin $\mathrm{C}$ deficiency causes immunosuppression, and may boost the immune system and act as an anti-inflammatory agent by inhibiting cytokine secretion. ${ }^{16}$

However, the effects of vitamin $\mathrm{C}$ supplementation on rhinitis symptoms in allergic rhinitis patients are still controversial. Some studies have reported that vitamin C may prove beneficial for allergic rhinitis sufferers. Helms and Miller reported that vitamin $\mathrm{C}$ sprayed into the nose reduced symptoms by reducing fluids that stimulate congestion and swelling in the nasal cavity. ${ }^{17}$ It has been shown that supplementing with at least 2 grams per day of vitamin $C$ prevents the release of histamine from white blood cells, and therefore may represent a promising non-pharmacological treatment therapy for allergic rhinitis patients. ${ }^{18}$ In contrast, a number of studies have reported that vitamin $\mathrm{C}$ has no effect on allergic sensitization ${ }^{19}$ and allergic rhinitis. ${ }^{20}$

Since aerobic moderate exercise training has been shown to be effective for improving the health status of allergic rhinitis patients, ${ }^{11-12}$ and data are equivocal as to whether vitamin C supplementation has positive effects on allergic rhinitis, an important question to answer is whether combining moderate aerobic exercise training with vitamin $\mathrm{C}$ supplementation will confer a greater protective effect in attenuating proinflammatory cytokine and allergic rhinitis symptoms compared to aerobic exercise training alone. Therefore, the primary aim of the present study was to evaluate the effects of moderate aerobic exercise training alone, and combined with vitamin $\mathrm{C}$ supplementation, on rhinitis symptoms, nasal cytokine secretion, nasal blood flow (NBF), and peak nasal inspiratory flow (PNIF). It was hypothesized that combining moderate aerobic exercise training with vitamin $\mathrm{C}$ supplementation would be more effective than moderate aerobic exercise training alone in reducing the allergic response in rhinitis patients.

\section{Methods}

\section{Study Design and Procedure}

The sample size calculation were performed by using $G^{*}$ power program at power $=0.9$ and effect size $=0.4$, the total sample size of 24 patients would be required. Rhinitis patients subjects were randomly assigned by the investigators allocated into 3 groups using a computerized random number generator: sedentary control, aerobic exercise training group, and aerobic exercise training combined with vitamin C supplementation group. Any steps concealed the sequence until interventions were assigned. During the study trial (8 weeks) the EX group underwent aerobic exercise training and received placebo supplementation, while the $\mathrm{Ex}+$ Vit. C group underwent aerobic exercise training and received Vitamin $C$ supplementation. The participants knew they were in the exercise or no-exercise but they did not know vitamin $\mathrm{C}$ or placebo. The control group did not engage in the aerobic exercise training protocol or receive any form of supplementation during the study trial. At pre - and post-study trial ( 8 weeks) body height, body weight, body fat, BMI, lung function, resting heart rate, blood pressure, VO2peak, total IgE, specific IgE, plasma Vit. $\mathrm{C}$ and malondialdehylde were measured. In addition, pre- and post-study trial rhinitis symptoms, peak nasal inspiratory flow, nasal blood flow and nasal secretions for cytokines analysis were evaluated as prior to and following a nasal challenge by house dust mite. The research assistants and medical laboratory scientists who assessed the outcomes and analyzed blood biochemistry were blinded to the interventions.

\section{Participants}

Thirty-three patients with allergic rhinitis, aged 18 to 45 years old, were recruited to this study from the Chulalongkorn university health service center. All allergic rhinitis subjects presented with clinical symptoms of persistent rhinitis (nasal congestion, sneeze, nasal itching, and running nose) for more than 4 days per week, and presented with a positive skin prick test (wheal diameter $>3 \mathrm{~mm}$.) to house dust mite (D. pteronyssinus) (ALK, Hørsholm, Denmark) and using normal saline as the negative control. Subjects with known asthma, chronic rhinosinusitis, hypertension or cardiovascular diseases, and a smoking habit, were excluded from participating in this study. Moreover, anterior rhinoscopy was performed to exclude anatomical abnormalities. Subjects were asked to refrain from taking antihistamine medication for at least 3 days prior to testing, and to abstain from using oral steroids and nasal steroids for at least 2 week prior to the start of the study. In addition, the subjects discontinued using leukotriene receptor antagonists for at least 1 week prior to testing. The subjects were not to have participated in a regular exercise program for at least 6 months prior to the start of the study, and to avoid taking any form of dietary supplement during the course of the study.

All subjects gave written informed consent prior to participation in the study. Medical and activity history were obtained via questionnaires. The study was approved by Institutional Review Board, Faculty of Medicine, Chulalongkorn University, COA No. 481/2011. This study was registered as a clinical trial with clinical trials.gov (study \# NCT 02123914).

\section{Exercise training protocol}

Subjects underwent an exercise training protocol for 30 minutes per session three times a week for 8 weeks at the Faculty of Sports Science, Chulalongkorn University, under the supervision of the primary investigators. Heart rate was continually monitored (Polar, Finland). The exercise training 
regimen consisted of 5 minutes of warm up and stretching, followed by walking and/or running on a treadmill (Landice, USA) at an intensity of $65-70 \%$ heart rate reserve for approximately $40 \mathrm{~min}$, followed by a cool down for $5 \mathrm{~min}$.

\section{Dietary supplementation}

The subjects ingested vitamin $\mathrm{C}$ tablets (The Government Pharmaceutical Organization, Thailand) 2 times/day (one pill of $1,000 \mathrm{mg}$ in the morning and one in the evening) for 2 months. The placebo and vitamin $\mathrm{C}$ tablets were identical in size and appearance to each other. The placebo tablets were manufactured by the Faculty of Sports Science, Chulalongkorn University.

\section{General physiological characteristics}

Heart rate $(\mathrm{HR})$ and blood pressure were taken after a 10-min rest period using digital sphygmomanometer (GE Dinamap CARESCAPE, V100, USA.). Body composition was performed using a bioelectrical impedance analyzer (InBody 220, Biospace, Seoul, Korea).

\section{Pulmonary function}

Pulmonary function (i.e. FVC and FEV1) was measured on all subjects using a calibrated computerized pneumotachograph spirometer (Spirotouch; Burdick, Inc., Deerfield, Wisconsin USA.) according to American Thoracic Society (ATS) recommendations. Subjects performed three acceptable spirograms, of which the largest and second largest forced vital capacity (FVC) and $\mathrm{FEV}_{1}$ values did not vary by more than $0.15 \mathrm{~L}$, and the best $\mathrm{FEV}_{1}$ and FVC maneuver kept for analysis.

\section{Peak aerobic capacity}

Each subject, wearing a nose clip, was required to run on a motorized treadmill (Landice, USA), which started at a speed of $1.7 \mathrm{mph}$, elevated at $10 \%$ and increased speed $0.8 \mathrm{mph}$ and elevated $2 \%$ every 3 minutes (Bruce protocol) until volitional exhaustion. During the exercise test, HR was continuously monitored by ECG and breath-by-breath analysis of expired gases was accomplished by indirect open circuit calorimetry (Cortex Metamax 3B, Germany).

\section{Blood collection and analysis}

Blood samples were obtained from an antecubital vein. Plasma IgE and specific IgE were measured with the standard procedures of the certified clinical laboratory at King Chulalongkorn Memorial Hospital. Plasma vitamin C concentrations were determined by Colorimetric Method in plasma after derivatization with 2,4-Dinitrophenyldrazine using spectrophotometer. The serum malondialdehyde (MDA) levels, a marker of oxidative stress, was determined using thiobarbituric acid reaction. ${ }^{21}$

\section{Rhinitis symptoms}

Nasal symptoms were assessed using Total Nasal Symptom Score (TNSS) questionnaire. ${ }^{22}$ The subjects were asked to score symptoms of persistent allergic rhinitis before and after each exercise protocol. The total nasal symptom scores were computed as the sum of four individual nasal symptom scores; nasal congestion, itching, sneezing, and rhinorrhea. The scores ranged from 0 to 3 scale $(0=$ none, $1=$ mild, $2=$ moderate, $3=$ severe). All participants, including the control group were supplied with a questionnaire and instructed to record their daily nasal symptoms.

\section{Peak nasal inspiratory flow}

Peak nasal inspiratory flow (PNIF) was measured using a peak nasal inspiratory flow meter (Clement Clark International model IN-CHECK ORAL, UK.) attached to an anesthesia mask. During the procedure, the subjects placed a mask, which is turned onto a plastic cylinder through which the air passes during inspiration, over the nose and mouth and inspired forcefully through the nose, with lips tightly closed. Inside the cylinder, there is a diaphragm that moves to the airflow, and the maximum peak flow is registered in a scale range from 30-370 $\mathrm{L} / \mathrm{min}$. During the procedure, the subjects placed a mask over the nose and mouth and inspired forcefully through the nose, with lips tightly closed. PNIF was measured before and after exercise.

\section{Nasal blood flow}

Nasal blood flow (NBF) was measured by laser doppler flowmetry (DRT4 moor instrument, UK.). All subjects rested in a room for 1 hour before the test. They were advised to breathe normally and not to cough, speak or move during the test. A side delivery endoscopic probe with a flexible nylon sleeve with a diameter of $1.34 \mathrm{~mm}$ was placed on the anterior surface of the nose. The nasal blood flow values before and after exercise in each protocol were then measured.

\section{Nasal challenge by house dust mite}

Each subject underwent a nasal challenge to house dust mite allergen (ALK, Hørsholm, Denmark). Bilateral nasal provocation used a nasal spray (metered-dose bottle) delivering a fixed volume of $0.125 \mathrm{~mL} /$ puff, with 1 puff in each nostril containing $1000 \mathrm{AU} / \mathrm{ml}$ of $D$. pteronyssinus. ${ }^{22}$ In pre-test and post-test, nasal secretion cytokine levels i.e. IL2 and IL4 were measured at baseline and after 5 minutes nasal challenge. Rhinitis symptoms, PNIF and NBF were measured at baseline, after 5, 15, 30, 45 and 60 minutes nasal challenge.

\section{Nasal secretion collection and handing}

Nasal secretion collection was performed bilaterally with filter paper strips $(7 \times 30 \mathrm{~mm}$ Whatman No.42, Whatman, Clifton, NJ). Three filter paper strips were sequentially placed on each anterior portion of the inferior turbinate for $10 \mathrm{~min}$. The filter paper strips were collected and put in test tubes, and then centrifuged at 3,000 rpm for $5 \mathrm{~min}$ at $4{ }^{\circ} \mathrm{C}$, after which the loose nasal secretions were immediately frozen at $-70{ }^{\circ} \mathrm{C}$ until later analysis.

\section{Cytokines analysis}

Nasal secretion values of cytokines, IL-2 and IL-4 were acquired. The cytokine levels in nasal secretions were determined using the human Th1/Th2/Th9/Th17/Th22 13 plex FlowCytomix Multiplex kits (Bender MedSystems, Vienna, Austria) according to the manufacturer's instructions. In brief, twenty-five microliters were incubated with two different sizes of polystyrol beads: 5.5 and 4.5 micron, coated with capture 
antibodies. After incubation, biotinylated detector antibodies and streaptavidin-PE were added. Data were acquired 1500 events within small beads (R2 beads) using a flow cytometer (BD FACSCalibur Flow Cytometer, USA). All data were analyzed by FlowcytomixTM Pro software (eBioscience, USA.).

\section{Statistical Analysis}

Data were analyzed using SPSS version 17 for Windows statistical software. The normality of the distribution of the variables was tested using a Shapiro-Wilk test. A Two way (group $\times$ time: $3 \times 2$ ) analysis of variance, followed by LSD multiple comparison test, was used to determine the significant differences in general physiological characteristics, plasma vitamin $\mathrm{C}$ and MDA. Data are expressed as mean \pm SEM. Rhinitis symptoms and total/specific IgE data were expressed as median values and compared by the Mann-Whitney test. Statistical difference was set at $\mathrm{p}<0.05$.

\section{Results}

As shown in Figure 1, the eligible participants were randomly allocated into three groups: sedentary control (CON; $\mathrm{n}=11$ ), aerobic exercise training group (EX; $\mathrm{n}=11$ ), and aerobic exercise training combined with vitamin $\mathrm{C}$ supplementation group $(\mathrm{EX}+\mathrm{Vit} . \mathrm{C} ; \mathrm{n}=11)$. A total of 6 subjects dropped out of the study. The three control subjects dropped out from scheduling difficulties. Three subjects dropped out from the exercise groups due to scheduling difficulties and physical discomfort. Therefore, the CON, Ex and Ex + Vit. C group were comprised of $8($ Male $=3$, Female $=5), 9($ Male $=3$, Female $=6)$ and $10($ Male $=3$, Female $=7)$ subjects, respectively.

\section{General physiological characteristics}

General characteristics are shown in Table 1. There were no significant differences in blood pressure, lung function and total and specific IgE among three groups of subjects. Both

\section{Enrollment}

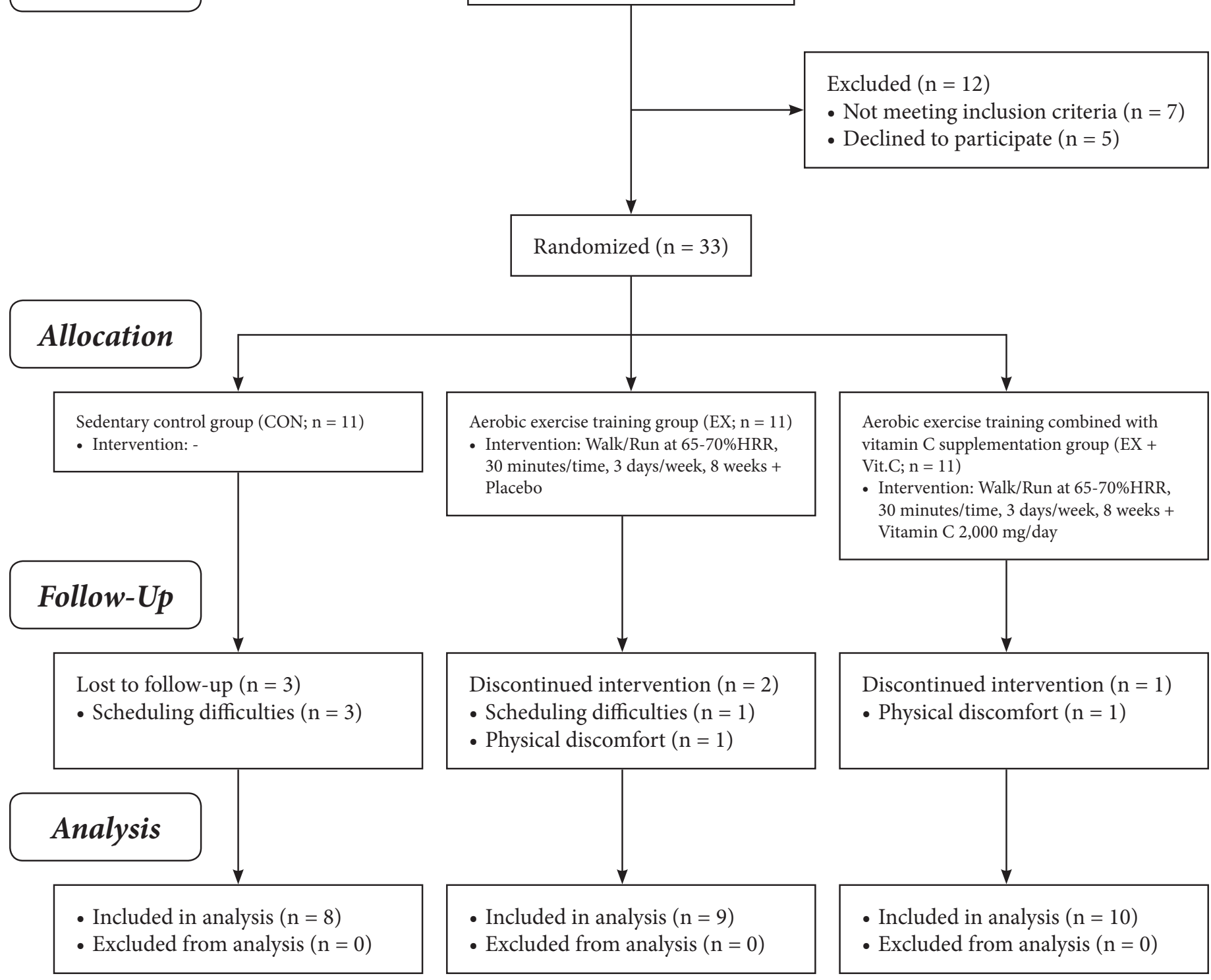

Figure 1. CONSORT 2010 flow diagram of participant allocation, follow-up and analysis. 
Table 1. The comparison of percent difference of the general physiological characteristics variables among in control group $(\mathrm{CON})$, exercise group $(\mathrm{EX})$ and exercise combined vitamin $\mathrm{C}$ supplementation group (EX + Vit. C).

\begin{tabular}{|c|c|c|c|c|c|c|}
\hline \multirow{2}{*}{ Variables } & \multicolumn{2}{|c|}{$\operatorname{CON}(\mathbf{n}=8)$} & \multicolumn{2}{|c|}{$\operatorname{EX}(n=9)$} & \multicolumn{2}{|c|}{ EX + Vit. C $(n=10)$} \\
\hline & Pre-test & Post-test & Pre-test & Post-test & Pre-test & Post-test \\
\hline Resting heart rate (b/min.) & $\begin{array}{c}78.12 \pm 2.52 \\
(71.37,84.87)\end{array}$ & $\begin{array}{c}80.25 \pm 1.46 \\
(74.46,86.03)\end{array}$ & $\begin{array}{c}79.33 \pm 3.17 \\
(72.97,85.69)\end{array}$ & $\begin{array}{l}72.55 \pm 2.43^{\star \dagger} \\
(67.10,78.00)\end{array}$ & $\begin{array}{c}83.40 \pm 3.28 \\
(77.36,89.43)\end{array}$ & $\begin{array}{l}75.60 \pm 3.26^{* \dagger} \\
(70.43,80.77)\end{array}$ \\
\hline Systolic BP (mmHg) & $\begin{array}{c}118.89 \pm 3.22 \\
(109.18,127.56)\end{array}$ & $\begin{array}{c}114.11 \pm 3.64 \\
(115.72,133.77)\end{array}$ & $\begin{array}{c}113.16 \pm 4.23 \\
(107.22,124.55)\end{array}$ & $\begin{array}{c}113.00 \pm 5.44 \\
(105.60,122.62)\end{array}$ & $\begin{array}{c}112.10 \pm 3.88 \\
(103.88,120.31)\end{array}$ & $\begin{array}{c}108.10 \pm 3.53 \\
(100.02,116.17)\end{array}$ \\
\hline Diastolic BP (mmHg) & $\begin{array}{c}74.12 \pm 2.78 \\
(65.86,82.38)\end{array}$ & $\begin{array}{c}74.12 \pm 2.74 \\
(67.54,80.71)\end{array}$ & $\begin{array}{c}73.11 \pm 4.53 \\
(65.32,80.89)\end{array}$ & $\begin{array}{c}69.22 \pm 3.86 \\
(63.02,75.42)\end{array}$ & $\begin{array}{c}70.10 \pm 3.59 \\
(62.71,77.48)\end{array}$ & $\begin{array}{c}65.50 \pm 2.24 \\
(59.61,71.38)\end{array}$ \\
\hline FVC (Liters) & $\begin{array}{l}3.08 \pm 0.25 \\
(2.57,3.59)\end{array}$ & $\begin{array}{l}2.93 \pm 0.27 \\
(2.41,3.45)\end{array}$ & $\begin{array}{l}2.56 \pm 0.20 \\
(2.07,3.04)\end{array}$ & $\begin{array}{l}2.64 \pm 0.20 \\
(2.14,3.13)\end{array}$ & $\begin{array}{l}2.63 \pm 0.23 \\
(2.17,3.08)\end{array}$ & $\begin{array}{l}2.71 \pm 0.23 \\
(2.24,3.18)\end{array}$ \\
\hline $\mathrm{FEV}_{1}$ (Liters) & $\begin{array}{l}2.69 \pm 0.25 \\
(2.14,3.23)\end{array}$ & $\begin{array}{l}2.70 \pm 0.24 \\
(2.22,3.17)\end{array}$ & $\begin{array}{l}2.50 \pm 0.17 \\
(1.99,3.01)\end{array}$ & $\begin{array}{l}2.59 \pm 0.16 \\
(2.14,3.04)\end{array}$ & $\begin{array}{l}2.16 \pm 0.28 \\
(1.67,2.64)\end{array}$ & $\begin{array}{l}2.52 \pm 0.23 \\
(2.09,2.95)\end{array}$ \\
\hline Body fat (\%) & $\begin{array}{c}21.30 \pm 3.59 \\
(13.18,29.41)\end{array}$ & $\begin{array}{c}21.35 \pm 3.52 \\
(13.77,28.92)\end{array}$ & $\begin{array}{c}26.55 \pm 4.26 \\
(18.90,34.20)\end{array}$ & $\begin{array}{c}26.07 \pm 3.90 \\
(18.93,33.22)\end{array}$ & $\begin{array}{c}21.52 \pm 3.21 \\
(14.26,28.77)\end{array}$ & $\begin{array}{c}20.64 \pm 2.97 \\
(13.86,27.41)\end{array}$ \\
\hline VO2peak (ml./kg./min.) & $\begin{array}{c}34.50 \pm 2.44 \\
(28.95,38.79)\end{array}$ & $\begin{array}{c}32.28 \pm 2.72 \\
(26.77,37.22)\end{array}$ & $\begin{array}{c}31.00 \pm 1.76 \\
(26.36,35.63)\end{array}$ & $\begin{array}{l}33.88 \pm 1.46^{\star \dagger} \\
(28.96,38.81)\end{array}$ & $\begin{array}{c}33.11 \pm 2.13 \\
(29.70,38.49)\end{array}$ & $\begin{array}{l}35.44 \pm 2.52^{\star \dagger} \\
(31.53,40.86)\end{array}$ \\
\hline${ }^{¥}$ Total IgE (IU/ml) & 229.50 & 289.50 & 271.00 & 236.00 & 233.50 & 215.50 \\
\hline${ }^{¥}$ D.pteronyssinus specific IgE (kUA/L) & 0.18 & 0.21 & 15.89 & 25.71 & 9.04 & 13.66 \\
\hline Plasma Vit C (mg/dl) & $\begin{array}{l}1.33 \pm 0.17 \\
(0.99,1.66)\end{array}$ & $\begin{array}{l}1.10 \pm 0.12 \\
(0.83,1.38)\end{array}$ & $\begin{array}{l}1.27 \pm 0.17 \\
(0.95,1.58)\end{array}$ & $\begin{array}{l}1.13 \pm 0.15 \\
(0.87,1.39)\end{array}$ & $\begin{array}{l}1.19 \pm 0.10 \\
(0.89,1.49)\end{array}$ & $\begin{array}{c}1.54 \pm 0.09^{*+\ddagger} \\
(1.29,1.79)\end{array}$ \\
\hline MDA $(\mu \mathrm{mol} / \mathrm{L})$ & $\begin{array}{l}0.36 \pm 0.07 \\
(0.19,0.52)\end{array}$ & $\begin{array}{l}0.48 \pm 0.13 \\
(0.35,0.61)\end{array}$ & $\begin{array}{l}0.60 \pm 0.07 \\
(0.44,0.75)\end{array}$ & $\begin{array}{c}0.20 \pm 0.01^{\star \dagger} \\
(0.79,0.32)\end{array}$ & $\begin{array}{l}0.57 \pm 0.13 \\
(0.42,0.71)\end{array}$ & $\begin{array}{c}0.24 \pm 0.05^{\star \dagger} \\
(0.12,0.35)\end{array}$ \\
\hline
\end{tabular}

Data are presented as mean \pm SEM. ( ${ }^{\ddagger}$ are median.) FVC $=$ Forced Vital Capacity, FEV $=$ Forced Expiratory Volume in 1 sec, VO2peak $=$ Peak oxygen consumption, $\mathrm{MDA}=$ Malondialdehyde ${ }^{\star} \mathrm{p}<0.05$ vs. pre-test ${ }^{\dagger} \mathrm{p}<0.05$ vs. CON ${ }^{\star} \mathrm{p}<0.05$ vs. EX

the EX and EX + Vit. C groups had significantly increased VO2peak ( $\mathrm{p}=0.004, \mathrm{p}=0.021)$ and significantly decreased resting heart rate $(\mathrm{p}=0.003, \mathrm{p}=0.001)$ and plasma malondialdehyde (MDA) levels $(\mathrm{p}=0.000, \mathrm{p}=0.000)$ after 8 weeks of training and also significant difference $($ all $\mathrm{p}<0.05)$ from CON group. Moreover, the plasma Vitamin $\mathrm{C}$ concentrations in the $\mathrm{Ex}+$ Vit.C group were significantly higher $(\mathrm{p}=0.012)$ than pre-test values and significant difference from CON $(p=0.022)$ and EX ( $p=0.027)$ groups. Total and specific IgE among three groups were not significant differences.

\section{Rhinitis symptoms}

After 8 weeks, the both EX and EX + Vit. C groups had significantly decreased in rhinitis symptoms such as nasal congestion ( $p=0.015, p=0.002)$, itching $(p=0.009, p=0.004)$, sneezing $(\mathrm{p}=0.013, \mathrm{p}=0.005)$, rhinorrhea $(\mathrm{p}=0.012, \mathrm{p}=0.014)$ and total rhinitis symptoms $(\mathrm{p}=0.001, \mathrm{p}=0.002)$. In addition, total rhinitis symptoms score was significantly lower in EX +
Vit.C group (3.50) compared with pre-test $(7.50, \mathrm{p}=0.015)$ and CON group (7.50, p = 0.004) (Table 2). Furthermore, Ex group had significantly decreased in total rhinitis symptoms difference from CON group $(\mathrm{p}=0.000)$. After nasal challenge, no changes in total rhinitis symptoms was found in the CON group (Figure 2A) but the total rhinitis symptoms in both EX (Figure 2B) and EX + Vit. C (Figure 2C) groups had significantly decreased at 15, 30, 45 and 60 minutes compare with pre-test (all $\mathrm{p}=0.000)$.

\section{Peak nasal inspiratory flow and nasal blood flow}

After 8 weeks, both the EX and EX + Vit. C groups had significantly increased $(\mathrm{p}=0.000, \mathrm{p}=0.016)$ PNIF (Figure 3A) and significantly decreased $(\mathrm{p}=0.002, \mathrm{p}=0.018) \mathrm{NBF}$ (Figure 3B) compared with pre-test.

After nasal challenge for 60 minutes, the CON group did not showed any significant difference in PNIF (Figure 4A) and NBF (Figure 4B). The both exercise groups had a significantly

Table 2. The comparison of percent difference of the rhinitis symptoms variables among in control group (CON), exercise group (EX) and exercise combined vitamin $\mathrm{C}$ supplementation group ( $\mathrm{EX}+\mathrm{Vit}$. $\mathrm{C})$.

\begin{tabular}{|c|c|c|c|c|c|c|}
\hline \multirow{2}{*}{ Variables } & \multicolumn{2}{|c|}{$\operatorname{CON}(n=8)$} & \multicolumn{2}{|c|}{$\operatorname{EX}(n=9)$} & \multicolumn{2}{|c|}{ EX + Vit. C $(n=10)$} \\
\hline & Pre-test & Post-test & Pre-test & Post-test & Pre-test & Post-test \\
\hline Nasal congestion & 2.00 & 2.00 & 2.00 & $1.00^{*}$ & 2.00 & $1.00^{*+}$ \\
\hline Itching & 3.00 & 2.00 & 3.00 & $1.00^{*}$ & 2.00 & $1.00^{*}$ \\
\hline Sneezing & 2.00 & 2.00 & 2.00 & $1.00^{*}$ & 2.00 & $1.00^{*+}$ \\
\hline Rhinorrhea & 2.00 & 2.00 & 2.00 & $1.00^{*}$ & 2.00 & $1.00^{*}$ \\
\hline Total rhinitis symptoms & 9.50 & 7.50 & 8.00 & $5.00^{*}$ & 8.00 & $3.50^{*+}$ \\
\hline
\end{tabular}

Data are Median. ${ }^{\star}$ p $<0.05$ vs. pre-test ${ }^{\dagger} \mathrm{p}<0.05$ vs. CON 
A. CON

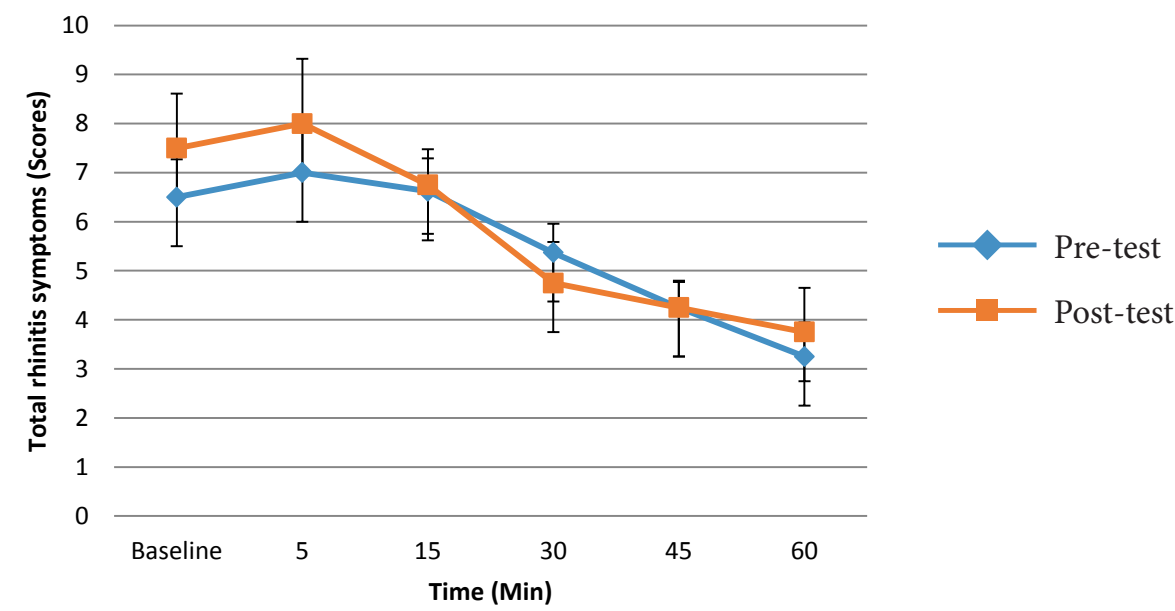

B.

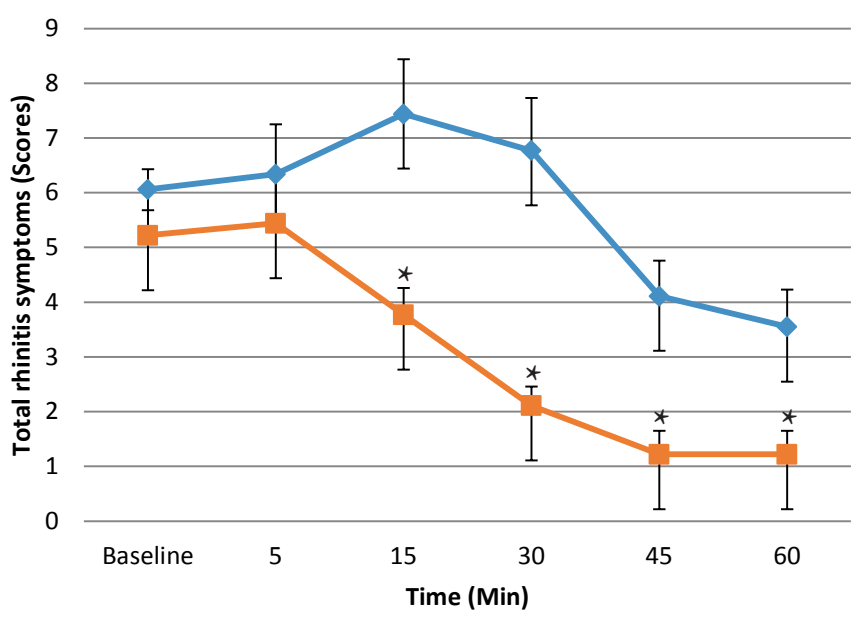

C.

EX + Vit.C

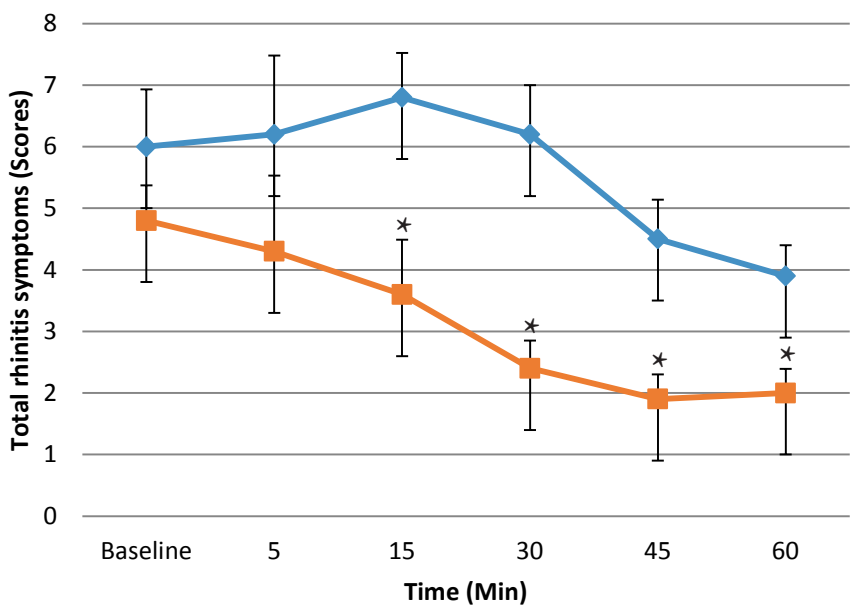

Figure 2. The comparison of total rhinitis symptoms after nasal challenge by house dust mite (D.pteronyssinus) between preand post-training in control group (A.), exercise group (B.) and exercise combined vitamin C supplementation group (C.). Data are presented as mean \pm SEM. ${ }^{\star} \mathrm{p}<0.05$ vs. Pre-test.

A.

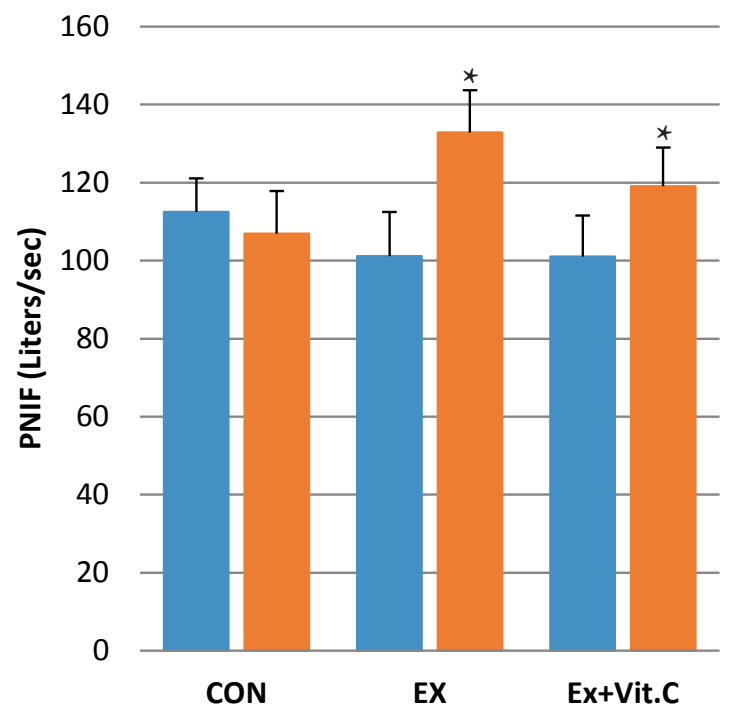

B. 60

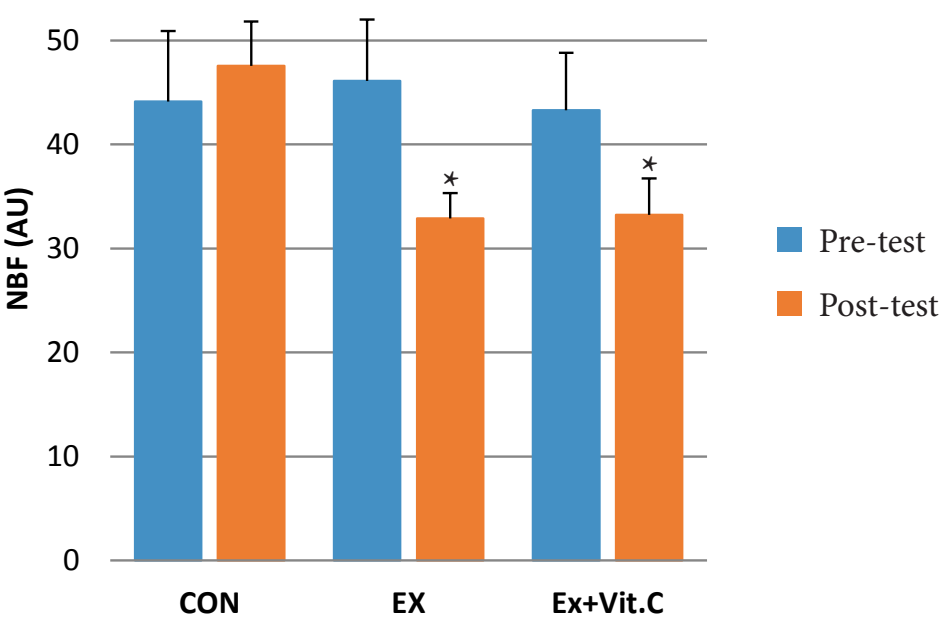

Figure 3. The comparison of peak nasal inspiratory flow (PNIF) (A.) and nasal blood flow (NBF) (B.) between pre- and post-training in control group $(\mathrm{CON})$, exercise group $(\mathrm{EX})$ and exercise combined vitamin $\mathrm{C}$ supplementation group (EX + Vit. C). Data are presented as mean \pm SEM. ${ }^{\star} \mathrm{p}<0.05$ vs. Pre-test 
A.

CON

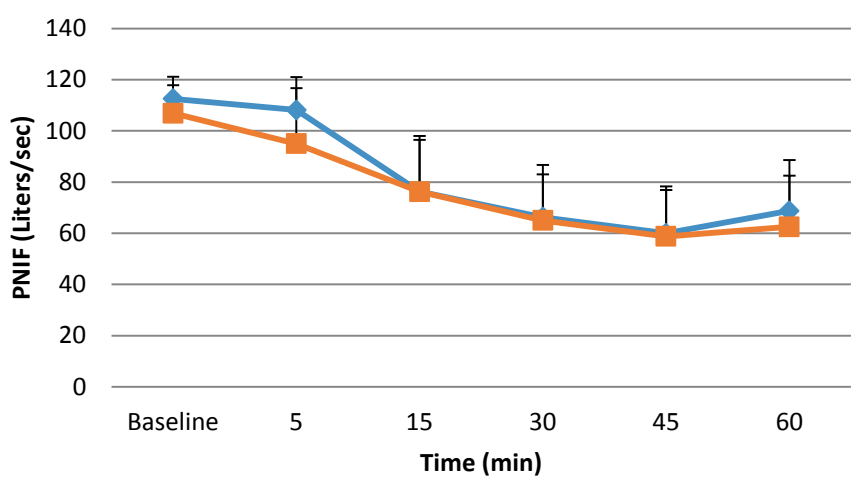

C.

EX

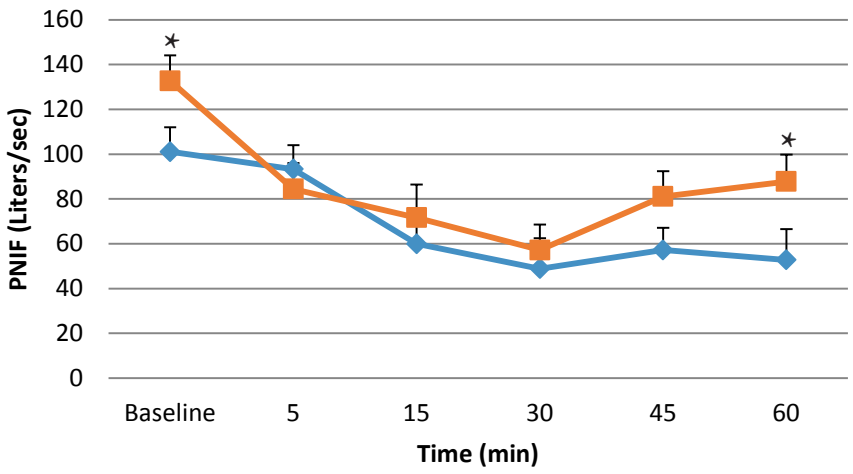

E.

EX + Vit.C

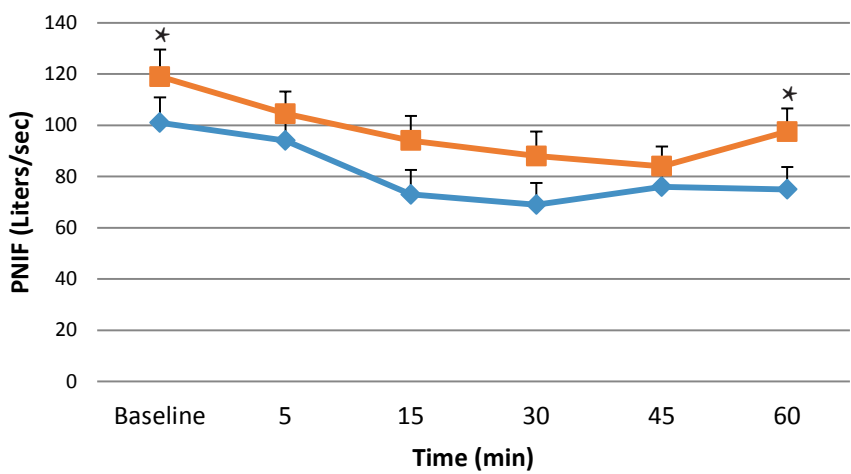

Pre-test
B.

CON

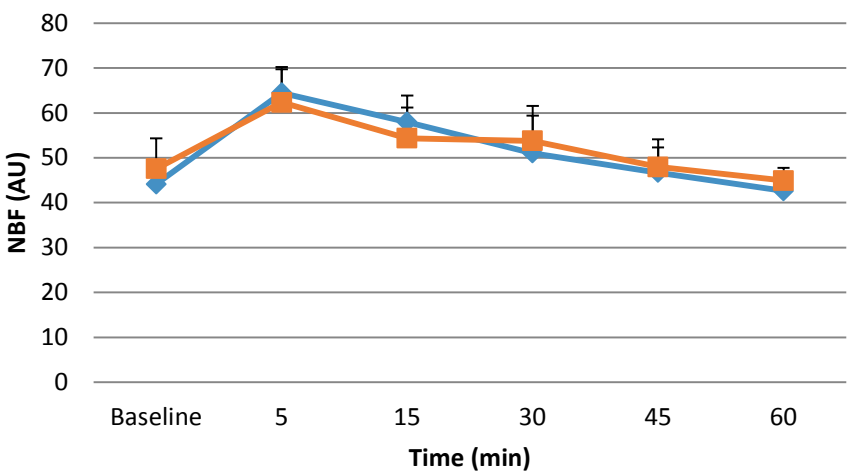

D.

EX

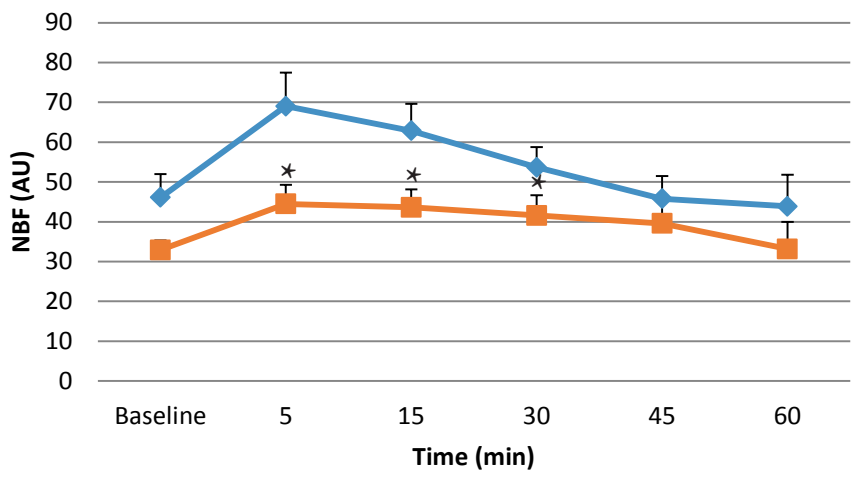

F.
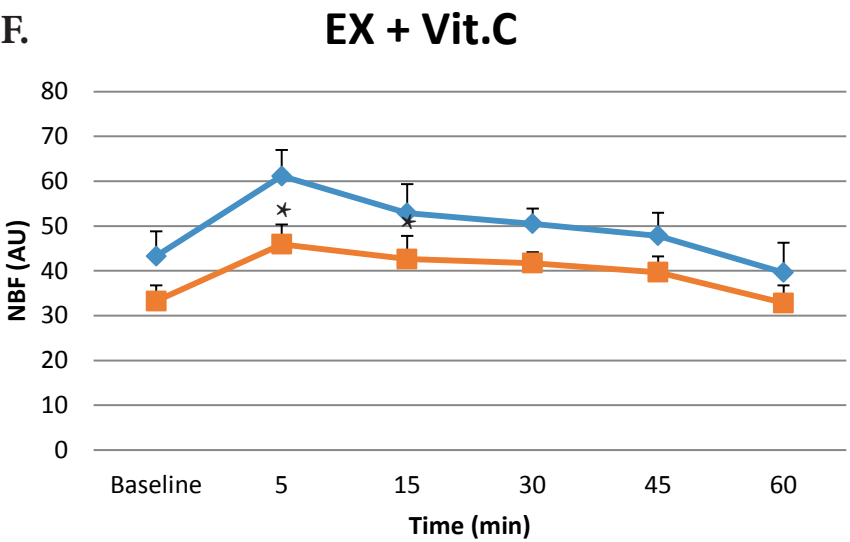

Post-test

Figure 4. The comparison of peak nasal inspiratory flow (PNIF) and nasal blood flow (NBF) after nasal challenge by house dust mite (D.pteronyssinus) between pre- and post-training in control group (A. and D.), exercise group (B. and E.) and exercise combined vitamin $\mathrm{C}$ supplementation group (C. and F.).

Data are presented as mean \pm SEM. ${ }^{*} \mathrm{p}<0.05$ vs. pre-test.

higher (all $\mathrm{p}=0.000)$ PNIF when compared with pre-test at baseline and 60 minutes (Figure $4 \mathrm{C}$ and $4 \mathrm{E}$ ) after nasal challenge. NBF decreased significantly after $5(p=0.000, p=0.004)$ and $15(\mathrm{p}=0.001, \mathrm{p}=0.048)$ minutes of nasal challenge compared with pre-test in the both EX and EX + Vit. C groups as shown in figure $4 \mathrm{D}$ and $4 \mathrm{~F}$.

\section{Cytokines levels in nasal secretion}

At pre-test, there were no significant difference in IL-2 (Figure 5A) and IL-4 (Figure 5C) among three groups at baseline and after nasal challenge by house dust mite (D.pteronyssinus). After 8 weeks, the both $\mathrm{EX}$ and $\mathrm{EX}+\mathrm{Vit}$. C groups had significantly higher $(\mathrm{p}=0.024, \mathrm{p}=0.019)$ baseline IL-2 (Figure 5B) and significantly lower $(\mathrm{p}=0.012, \mathrm{p}=0.025)$ baseline IL-4 (Figure 5D) compared with the control group. Besides, both EX and EX + Vit. C groups had significantly decreased $(\mathrm{p}=0.001, \mathrm{p}=0.008)$ in IL-4 when compared with pre-test (Figure 5D). After nasal challenge by house dust mite (D.pteronyssinus), the IL-2 in the both EX and EX + Vit. C groups was significantly higher $(\mathrm{p}=0.018, \mathrm{p}=0.010)$ than the 
Pre-test

A. 140

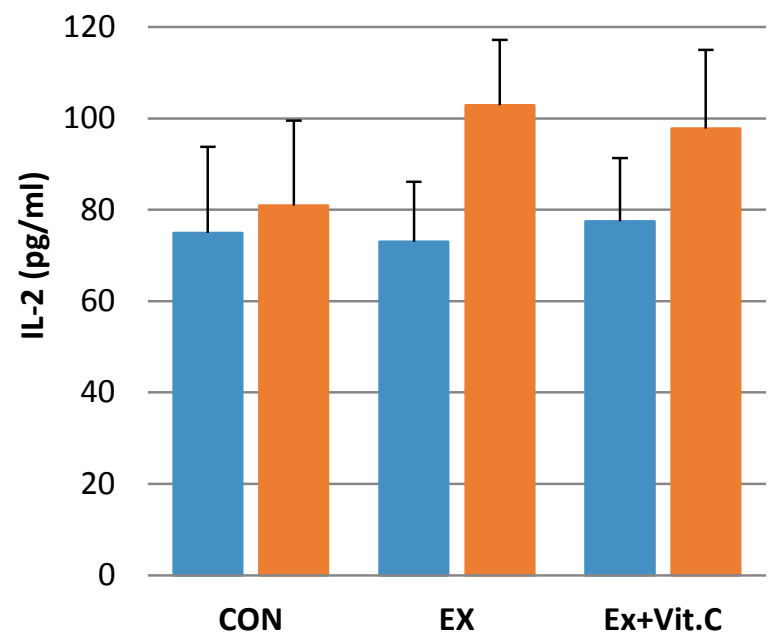

C. 60

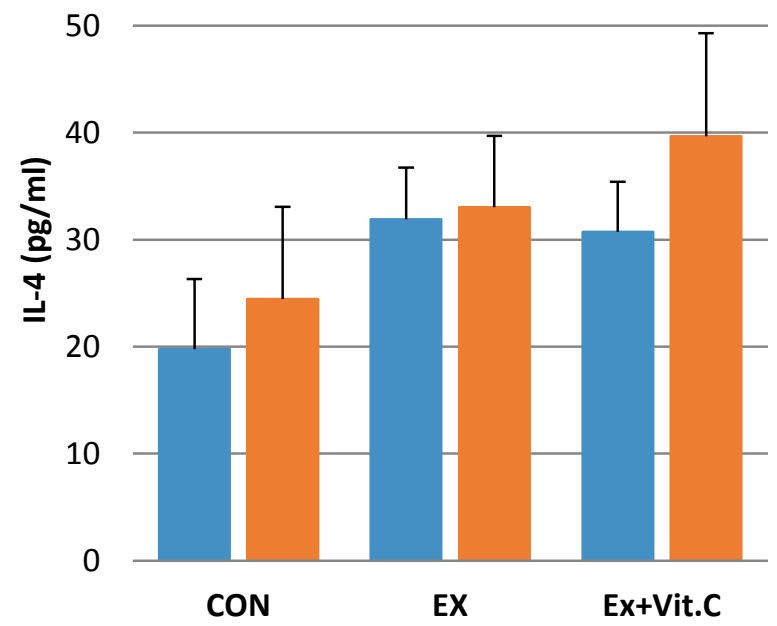

B.

Post-test

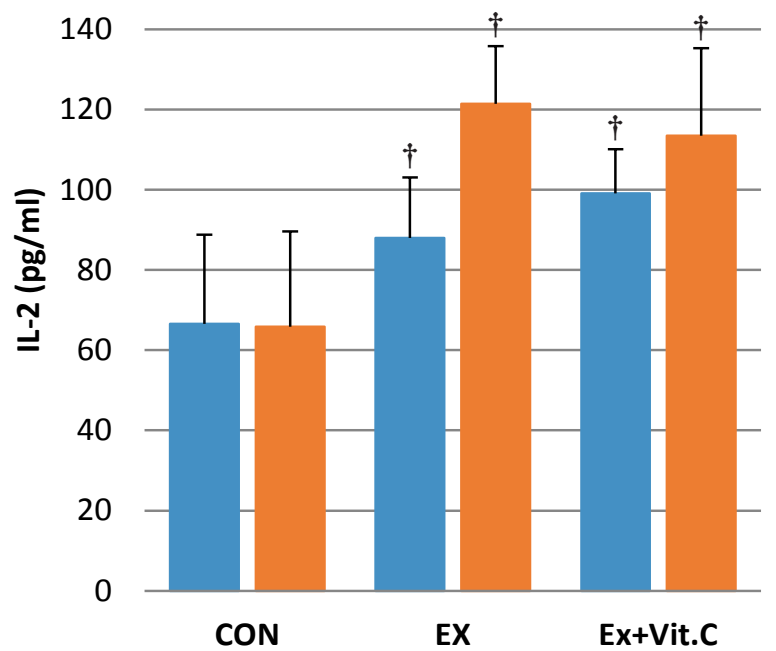

D. 60

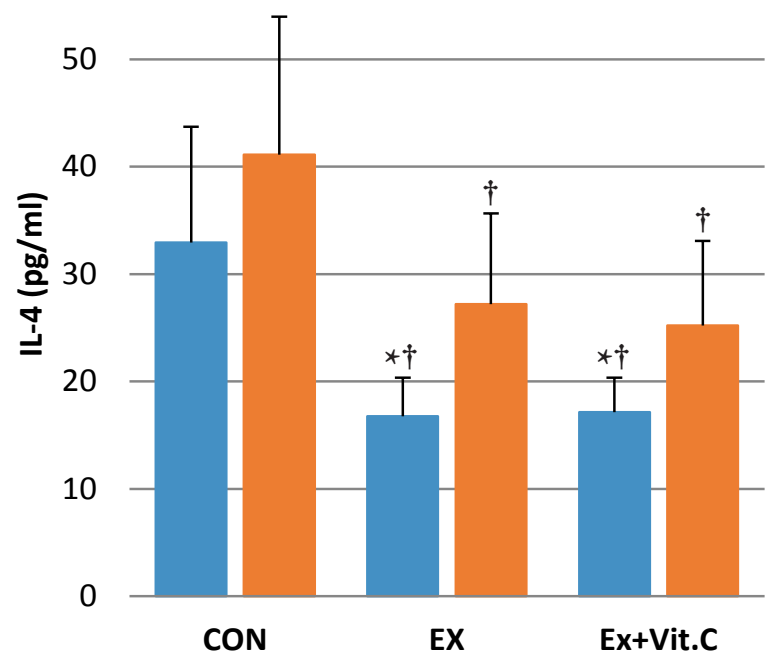

Challenge

Figure 5. The comparison of cytokine levels in nasal secretion at baseline and after 5 minutes nasal challenge between pre-test and post-test and among three groups of subjects: control group (CON), exercise group (EX) and exercise combined vitamin $\mathrm{C}$ supplementation group (EX + Vit. C).

Data are presented as mean \pm SEM. ${ }^{\star} \mathrm{p}<0.05$ vs. pre-test $\dagger \mathrm{p}<0.05$ vs. CON

CON group (Figure 5B) but the IL-4 in the both EX and EX + Vit. C groups were significantly lower $(p=0.009, p=0.012)$ than the CON group (Figure 5D).

\section{Discussion}

The principal finding of the present study is that both exercise training alone and exercise training combined with vitamin C supplementation reduced rhinitis symptoms in allergic rhinitis patients. The improvement in clinical symptoms, as a consequence of aerobic training, was supported by reduced nasal blood flow and peak nasal inspiratory flow rate. Besides, the increased IL- 2 and decreased IL- 4 cytokine levels compared to control patients were also shown. However, the total and specific-IgE to house dust mites did not change between pre- and post-tests in either group.

The present study showed that aerobic exercise training reduced allergic rhinitis symptoms. The reduction in rhinitis symptoms following the aerobic exercise training may be due to decreased nasal resistance resulted from decreased sympathetic vasoconstriction in the nasal mucosa. ${ }^{23}$ The fall in nasal resistance may be caused, at least partly, by reducing blood flow, ${ }^{24}$ leading to reduced nasal congestion. ${ }^{25}$ Our finding that PNIF increased following aerobic exercise training is in agreement with Marioni et al. ${ }^{26}$ who reported that the mean PNIF after prolonged exhaustive exercise was 
significantly higher than the mean PNIF value found before exercise. They suggested that PNIF sensitivity and reliability also in determining the changes in nasal patency, which occurred after physical exercise.

Allergic inflammation is associated with the production of IL-4, IL-13, and IL-5, which are responsible for IgE production by $\mathrm{B}$ cells, eosinophil activation and recruitment, and mucus production. ${ }^{2}$ A recent study reported that the higher levels of IL-4 occur in the nasal fluid of allergic rhinitis patients compared to non-allergic controls. ${ }^{27}$ In contrast, differentiated Th1 cells secrete interferon- $\gamma$ and IL-2, which are important in intracellular destruction of phagocytosed microbes. ${ }^{28}$ In the present study, no significant changes in terms of total IgE and specific $\operatorname{IgE}$ to house dust mites were detected after 8 weeks of aerobic exercise training. However, we did observe that, following the aerobic exercise training, IL-4 levels were significantly lower than pre-training at baseline and after nasal challenge with house dust mite. It has been suggested that aerobic exercise training could be attributed to decrease levels of IL-4. ${ }^{29-30}$ Nevertheless, Shimizu et al. ${ }^{31}$ found that moderate exercise training 5-days a week for 6 months did not change in IL-4 cytokine in blood.

In the present study, IL-2 levels in nasal secretion increased in patients following the moderate exercise training compared to those in the control group. Arai et al. ${ }^{32}$ reported that longterm endurance training can enhance IL-2 production comparable to levels found in young male subjects indicating that chronic exercise could delay immunosenescence. According to our data, we suggest that the improvement in clinical symptoms in allergic rhinitis patients may be a consequence of a cytokine deviation after regular exercise training. Previous studies have reported that the anti-inflammatory effects of aerobic exercise training could be attributed to decrease levels of IL-4, IL-5, IgE, and also an increase in anti-inflammatory cytokines. ${ }^{29-30}$ The potential mechanism as to how moderate exercise training modulates the cytokine response has not clearly been elucidated. One possible mechanism is that the improvement in VO2peak following the aerobic exercise training may attenuate oxidative stress which in turn, may alter the inflammatory cytokine expression pattern. ${ }^{34}$ The moderate exercise training -induced improvement in inflammatory status may also result from the reduction of antigen-specific $\mathrm{T}$ helper cells migration due to decreasing chemokine receptor function in these subjects. ${ }^{34}$ Since plasma MDA declined after 8 weeks of aerobic exercise training, we speculate that moderate exercise training conferred a beneficial effect by ameliorating oxidative stress, possibly as a result of a deviation of cytokine response in nasal secretion after exercise.

In the present study, it was clearly seen that nasal symptoms, peak nasal inspiratory flow, and nasal blood flow in both patient groups who underwent exercise training alone, and exercise training plus vitamin $\mathrm{C}$ supplement, were significantly improved compared to baseline symptoms and significantly better compared to data in the control patients; however, there was no significant difference between the aerobic exercise training and exercise training plus vitamin $\mathrm{C}$ group. As the normal range $(0.6-2.0 \mathrm{mg} / \mathrm{dL})^{35}$ of vitamin $\mathrm{C}$ status in our allergic rhinitis participants, supplemental vitamin $\mathrm{C}$ is not likely to show any benefit. Our study suggests that the supplementary vitamin $\mathrm{C}$ in allergic rhinitis patients has no additional benefit in terms of clinical improvement if they are amply nourished and have adequate exercise. Future studies regarding the appropriate dosage of vitamin $\mathrm{C}$ supplementation for allergic rhinitis patients are warranted.

There are a number of limitations in the present study that should be emphasized. First the presently study did not include a group that performed no exercise but were vitamin C supplemented. Second, the number of subjects in each intervention group may be considered small. Third, the control group did not receive a placebo supplement.

\section{Conclusions}

The present study demonstrate that both aerobic exercise training alone and aerobic exercise training combined with vitamin $\mathrm{C}$ have beneficial effects in allergic rhinitis patients by reducing rhinitis symptoms. The extensive benefits on immune function were to improve cytokine deviation by increase IL-2 and decrease IL-4. Moreover, cardiorespiratory and clinical symptoms (PNIF and NBF) improvement as well as oxidative stress reduction were found in patients with allergic rhinitis following aerobic exercise training. This study clearly confirms that aerobic exercise significantly improved clinical of allergic rhinitis and cytokine profiles. However, due to the limited power of our small sample size, we were unable to determine as to whether adding vitamin $\mathrm{C}$ supplementation to exercise would confer a greater benefit than exercise alone in improving the clinical response in allergic rhinitis patients. A larger randomized controlled trial is thus warranted.

\section{Acknowledgements}

We are indebted to all volunteers. We would like to thank Supranee Buranapraditkun, Ph.D. for cytokines analysis. This study was supported by the Ratchadaphiseksomphot Endowment Fund, Chulalongkorn University and Faculty of Sports Science Fund, Chulalongkorn University.

\section{References}

1. Bousquet PJ, Demoly P, Devillier P, Mesbah K, Bousquet J. Impact of allergic rhinitis symptoms on quality of life in primary care. Int Arch Allergy Immunol. 2013;160:393-400.

2. Wheatley LM, Togias AN. Clinical practice Allergic rhinitis. Engl J Med. 2015;372:456-63.

3. Lakhani N, North M, Ellis AK. Clinical Manifestations of Allergic Rhinitis. J Aller Ther. 2012;S5:007.

4. Dimeo F, Pagonas N, Seibert, Arndt R, Zidek W, Westhoff TH. Aerobic exercise reduces blood pressure in resistant hypertension. Hypertension. 2012;60:653-8.

5. Yalamanchi SV, Stewart KJ, Ji N, Golden SH, Dobs A, Becker DM, et al. The relationship of fasting hyperglycemia to changes in fat and muscle mass after exercise training in type 2 diabetes. Diabetes Res Clin Pract. 2016;122:154-61.

6. Chengji W, Shoujun H. Aerobic exercise can ameliorate heart function in patients with myocardial infarction through up-regulating M3 receptor. IJC Metabolic \& Endocrine. 2016;13:1-5.

7. Keating SE, Hackett DA, Parker HM, O'Connor HT, Gerofi JA, Sainsbury A, et al. Effect of aerobic exercise training dose on liver fat and visceral adiposity. J Hepatol. 2015;63:174-82.

8. Silvers WS, Poole JA. Exercise-induced rhinitis: a common disorder that adversely affects allergic and nonallergic athletes. Ann Allerg Asthma Im. 2006;96:334-40. 
9. Valero A, Serrano C, Valera JL, Barberá A, Torrego A, Mullol J, et al. Nasal and bronchial response to exercise in patients with asthma and rhinitis: the role of nitric oxide. Allergy. 2005;60:1126-31.

10. Aldred S, Love JA, Tonks LA, Stephens E, Jones DS, Blannin AK. The effect of steady state exercise on circulating human IgE and IgG in young healthy volunteers with known allergy. J Sci Med Sport. 2010;13:16-9.

11. Tongtako W, Klaewsongkram J, Jaronsukwimal N, Buranapraditkun S, Mickleborough TD, Suksom D. The effect of acute exhaustive and moderate intensity exercises on nasal cytokine secretion and clinical symptoms in allergic rhinitis patients. Asian Pac J Allergy Immunol. 2012;30:185-92.

12. Silva RA, Vieira RP, Duarte ACS, Lopes FD, Perini A, Mauad T, et al. Aerobic training reverses airway inflammation and remodelling in an asthma murine model. Eur Respir J. 2010;35:994-1002.

13. Enstrom JE. Epidemiology of Vitamin C. In: Quah SR, Cockerham W, editors. International Encyclopedia of Public Health. 2nd ed. Boston: Elsevier; 2017. p. 559-68.

14. Afolayan AJ, Wintola OA. Dietary supplements in the management of hypertension and diabetes - a review. Afr J Tradit Complement Altern Med. 2014;11:248-58.

15. Hemilä H1, Chalker E. Vitamin C for preventing and treating the common cold. Cochrane Database Syst Rev. 2013;1:CD000980.

16. Chambial S, Dwivedi S, Shukla KK, John PJ, and Sharma P. Vitamin C in disease prevention and cure: an overview. Indian J Clin Biochem. 2013;28:314-28.

17. Helms S, Miller A. Natural treatment of chronic rhinosinusitis. Altern Med Rev. 2006;11:196-207.

18. Bucca C, Rolla G, Oliva A, Farina JC. Effect of vitamin C on histamine bronchial responsiveness of patients with allergic rhinitis. Ann Allergy. 1990;65:311-4.

19. Forastiere F, Pistelli R, Sestini P, Fortes C, Renzoni E, Rusconi F, et al. Consumption of fresh fruit rich in vitamin $\mathrm{C}$ and wheezing symptoms in children. SIDRIA Collaborative Group, Italy (Italian Studies on Respiratory Disorders in Children and the Environment). Thorax. 2000;55:283-8.

20. Kompauer I, Heinrich J, Wolfram G, Linseisen J. Association of carotenoids, tocopherols and vitamin $\mathrm{C}$ in plasma with allergic rhinitis and allergic sensitisation in adults. Public Health Nutr. 2006;9:472-9.

21. Spirlandeli AL, Deminice R, Jordao AA. Plasma malondialdehyde as biomarker of lipid peroxidation: effects of acute exercise. Int J Sports Med. 2014;35:14-8.
22. Chusakul S, Phannaso C, Sangsarsri S, Aeumjaturapat S, Snidvongs K House-dust mite nasal provocation: a diagnostic tool in perennial rhinitis. Am J Rhinol Allergy. 2010;24:133-6.

23. Olson LG, Strohl KP. The response of the nasal airway to exercise. Am Rev Respir Dis. 1987;135:356-9.

24. Clarke RW. The differential effect of isotonic and isometric exercise on nasal blood flow as measured by laser doppler analysis. Otolaryngology. 1996;115:130.

25. Ramey JT, Bailen E, Lockey RF. Rhinitis medicamentosa. J Invest Allerg Clin. 2006;16:148-55.

26. Marioni G, Ottaviano G, Staffieri A, Zaccaria M, Lund VJ, Tognazza E, et al Nasal functional modifications after physical exercise: olfactory threshold and peak nasal inspiratory flow. Rhinology. 2010;48:277-80.

27. Scavuzzo MC, Rocchi V, Fattori B, Ambrogi F, Carpi A, Ruffoli R, et al. Cytokine secretion in nasal mucus of normal subjects and patients with allergic rhinitis. Biomed Pharmacother. 2003;57:366-71.

28. Ngoc LP, Gold DR, Tzianabos AO, Weiss ST, Celedón JC. Cytokines, allergy, and asthma. Curr Opin Allergy Clin. 2005;5:161-6.

29. Pastva A, Estell K, Schoeb TR, Schwiebert LM. RU486 blocks the anti -inflammatory effects of exercise in a murine model of allergen-induced pulmonary inflammation. Brain Behav Immun. 2005.;19:413-22.

30. Vieira RP, de Andrade VF, Duarte AC, Dos Santos AB, Mauad T, Martins MA, et al. Aerobic conditioning and allergic pulmonary inflammation in mice. II. Effects on lung vascular and parenchymal inflammation and remodeling. Am J Physiol Lung Cell Mol Physiol. 2008;295:L670-9.

31. Shimizu K, Kimura F, Akimoto T, Akama T, Tanabe K, Nishijima T, et al Effect of moderate exercise training on T-helper cell subpopulations in elderly people. Exerc Immunol Rev. 2008;14:24-37.

32. Arai MH, Duarte AJ, Natale VM. The effects of long-term endurance training on the immune and endocrine systems of elderly men: the role of cytokines and anabolic hormones. Immun Ageing. 2006;3:9.

33. Smart NA, Larsen AI, Le Maitre JP, Ferraz AS. Effect of exercise training on interleukin-6, tumour necrosis factor alpha and functional capacity in heart failure. Cardiol Res Pract. 2011;2011:532620.

34. Dugger KJ, Chrisman T, Jones B, Chastain P, Watson K, Estell K, et al Moderate aerobic exercise alters migration patterns of antigen specific $\mathrm{T}$ helper cells within an asthmatic lung. Brain Behav Immun. 2013;34:67-78.

35. Kraemer, C.M. Vitamin C (Ascorbic Acid) [Internet]. New York: WebMD LLC; c1994- 2017 [updated 2014 Nov 21; cited 2016 Jan 28]. Available from: http://emedicine.medscape.com/article/2088649- 493 overview. 